\title{
Two newborn babies with generalized arterial calcification of infancy, two new mutations
}

\author{
Hacer Yapıcıŏlu-Yıldızdaş ${ }^{1}$, Nazan Özbarlas², Sevcan Erdem², Mehmet Bertan Yılmaz ${ }^{3}$, \\ Ferda Özlüi ${ }^{1}$, Selim Büyükkurt ${ }^{4}$, Süreyya Soyupak ${ }^{5}$, Utku Güllü${ }^{2}$, Kadri Karaer ${ }^{6}$ \\ Division of ${ }^{1}$ Neonatology, ${ }^{2}$ Pediatric Cardiology, Department of Pediatrics, and Departments of ${ }^{3}$ Medical Biology, ${ }^{4}$ Gynecology \\ and Obstetrics, and ${ }^{5}$ Radiology, Çukurova University, Faculty of Medicine, Adana; Intergen Laboratory6, Ankara, Turkey. \\ E-mail: hyapicioglu@cu.edu.tr \\ Received: 1st December 2015, Revised 31st March 2016, Accepted: 28th April 2016
}

SUMMARY: Yapıcıŏlu-Yıldızdaș H, Özbarlas N, Erdem S, Yılmaz MB, Özlü F, Büyükkurt S, Soyupak S, Güllü U, Karaer K. Two newborn babies with generalized arterial calcification of infancy, two new mutations. Turk J Pediatr 2016; 58: 419-423.

Idiopathic generalized arterial calcification of infancy-1 (GACI-1) is a rare and potentially lethal disease characterized by diffuse calcification of large and medium-sized arteries such as aorta, renal, pulmonary, cerebral and mesenteric arteries. Here we report two new mutations in two newborn babies with GACI-1 treated with bisphosphonates, and their progress in the first year of life.

Key words: idiopathic generalized arterial calcification, newborn.

Idiopathic generalized arterial calcification of infancy-1 (GACI-1) is a rare and potentially lethal disease characterized by diffuse calcification of large and medium-sized arteries such as aorta, renal, pulmonary, cerebral and mesenteric arteries. The unregulated excessive calcium deposition is due to low levels of inorganic pyrophosphate (PPi) in the patients secondary to reduced PPi-generating ectonucleotidepyrophosphatase 1 (ENPP1) enzyme, encoded by the ENPP1 gene on $6 \mathrm{q} 23^{1}$. Mortality rate is high in infancy period because of refractory hypertension, myocardial infarction and rapidly progressive left sided heart failure ${ }^{1-3}$. GACI-2 is caused by mutation in the ABCC6 gene on chromosome 16p13.112.

There are case reports about use of biphosphonates, synthetic pyrophosphate analogs, in GACI patients and their useful effects $^{3}$. Here we report two new mutations in two newborn babies with GACI-1 treated with biphosphonates and their progress in the first year of life.

\section{Case 1}

The female patient was the second child of Turkish consanguineous parents. Mother had 8 previous pregnancies: five miscarriages, two intrauterine exitus due to non-immune hydrops fetalis, one male baby died at 1 year old age because of shunt infection due to congenital hydrocephalus, and 3 years old age healthy boy. The baby was delivered at 36 th gestational age, birth weight 2240 g, Apgar scores 9 and 10 and referred to the unit for prematurity. Heart rate was 140/ min, respiratory rate was $65 / \mathrm{min}$, blood pressure was $62 / 34 \mathrm{~mm} \mathrm{Hg}$. She had transient tachypnea of newborn and as she had a grade 1 murmur, echocardiography was performed on the 3rd day which revealed normal systolic function with septal hypertrophy (IVSd: 6.9 $\mathrm{mm}$ ), brightness and hyperechogenicity of the coronary arteries, pulmonary annulus, aorta, aortic arch, descending aorta, subclavian, carotid, celiac and renal arteries (Figs 1-2). There was no calcification in the vessels and joints in X-rays.

Antenatal echocardiography was normal in the second trimester. GACI was diagnosed and biphosphonate treatment (pamidronate, $0.1 \mathrm{mg} / \mathrm{kg} /$ day for 3 consecutive days every 3 months) was started, but afterwards parents refused the treatment until genetic analysis report was finalised. She was hospitalized for 9 days. Genetic analysis revealed the homozygous 
p.W322 (c.966g >A) mutation in ENPP1 on both alleles when she was 4 months old. The parents were carriers of the same mutation; she is treated with pamidronate $(0.5 \mathrm{mg} / \mathrm{kg} /$ day for 3 days) at 3 month intervals. She is now 9 months old and $8 \mathrm{~kg}$ (25-50\%). Blood pressure is normal. Abdominal ultrasonography at 9 months revealed no calcification in descending aorta, renal and celiac arteries; however there was no change on echocardiography. Serum calcium, phosphorus, parathormone, and urinary phosphate levels were normal after the last treatment.

\section{Case 2}

The male newborn was born at 40 week of gestation. His birth weight was 3215 g, and Apgar scores were 9 and 10. Fetal echocardiography in 35th week of gestation revealed hyperechogenicity in pulmonary artery, ductus arteriosus and aorta (Fig 3). After birth, echocardiography showed hyperechogenicity on coronary arteries, aorta, pulmonary artery, ductus arteriosus, descending and abdominal aorta, celiac and renal arteries and also in renal parenchyma. On the 9th day of life, ductus arteriosus was patent, captopril and furosemide treatment was begun. Intravenous pamidronate $(0.1 \mathrm{mg} / \mathrm{kg} /$ day for 3 consecutive days every month) was started for GACI. Parents were cousins. The baby had homozygous mutation of p.G738R (c.2212G>A). He had another two courses of pamidronate $(0.5 \mathrm{mg} / \mathrm{kg} / \mathrm{day}$, for 3 days, on $3^{\text {rd }}$ and $6^{\text {th }}$ months of life). He was treated with oral pamidronate for 2 months as parent denied hospitalization however as they had difficulty obtaining the oral form of the drug, intravenous pamidronate treatment was initiated again. When he was 10 months old, he was diagnosed with hypertension (160/95 mmHg). Renal arteries were calcific and stenotic. Electrocardiogram showed left ventricular hypertrophy, ST depression during tachycardia. Echocardiography revealed left ventricular hypertrophy and valvular calcification on aorta. The velocity was $2.3 \mathrm{~m} / \mathrm{sc}$ between left ventricle and aorta. There was mild aortic regurgitation. Captopril was stopped, propranolol and intravenous pamidronate treatment were begun. Afterwards blood pressure was normalised. He is now 11 months old and his weight is $9.2 \mathrm{~kg}(25-50 \%)$.

\section{Discussion}

GACI is inherited in an autosomal recessive pattern, given the preponderance of cases in families. GACI-1 is caused by mutation in ENPP1 gene. ENNP1 is expressed on osteoblasts, chondrocytes and vascular smooth muscle cells and extracellular nucleotide triphosphates to generate PPi. Inorganic pyrophosphate is a potent inhibitor of mineralization ${ }^{4,5}$. For this reason ENPP1 deficiency in GACI reduces extracellular PPi levels and predisposes to ectopic calcification of arteries, joints and soft tissues ${ }^{2}$. The disease was described by Menten and Fetterman ${ }^{6}$ in 1948 in 3 male infants, and to date, about 200 cases have been reported. Most of the patients have symptoms during prenatal and early infancy period such as polyhydramnios, hydrops, heart failure, respiratory distress, heart failure, hypertension, failure to thrive, or convulsions ${ }^{7,8}$. In Chong and Hutchins's study ${ }^{8}$, they reviewed 161 case reports in 110 publications and found that $48 \%$ of patients presented in utero or shortly after birth and $52 \%$ presented later at a median age of 3 months old. The main pathologic finding in these infants is the calcification of arterial structures beginning in the internal elastic lamina extending into the intima and media. The most affected arteries are aorta, hepatic, pulmonary, coronary and renal arteries in early diagnosis and coronary, renal, pulmonary arteries, and aorta in late diagnosis ${ }^{8}$. Periarticular calcification had been detected prenatally or in infancy in about $29 \%$ of the patients ${ }^{3}$. Also hearing loss has been reported in the first days of life in patients with GACI, and in ENPP1 knock-out mice and in other diseases of pyrophosphate metabolism, probably due to inner ear supplying arteries occlusion ${ }^{9}$.

In our cases there were no obvious symptoms at birth although we have seen extensive calcification in aorta, coronary, pulmonary, celiac arteries and renal arteries. Also we have not detected periarticular calcification or hearing loss in our patients. In the first patient, the admission cause was prematurity and respiratory distress; however the cause of respiratory distress was transient tachypnea of newborn and dissolved soon. The mother of this case had five miscarriages, two intrauterine exitus due to non-immune hydrops fetalis, one 


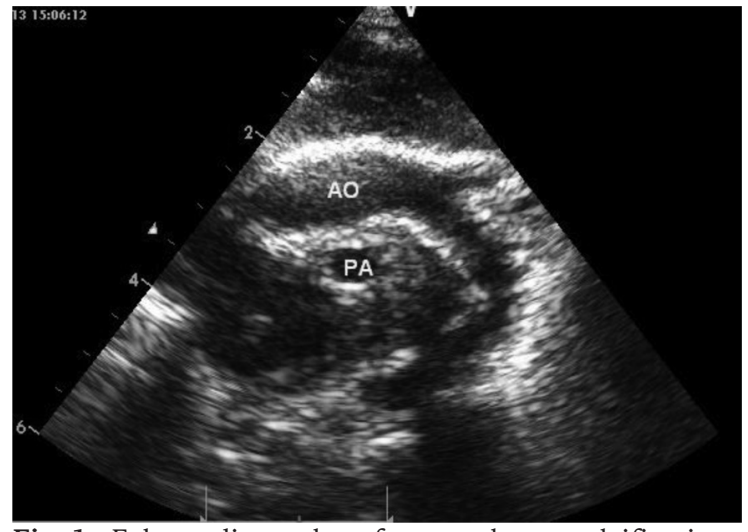

Fig 1. Echocardiography of aorta shows calcifications of ascending, transvers and descending aorta (AO) and pulmonary artery (PA)

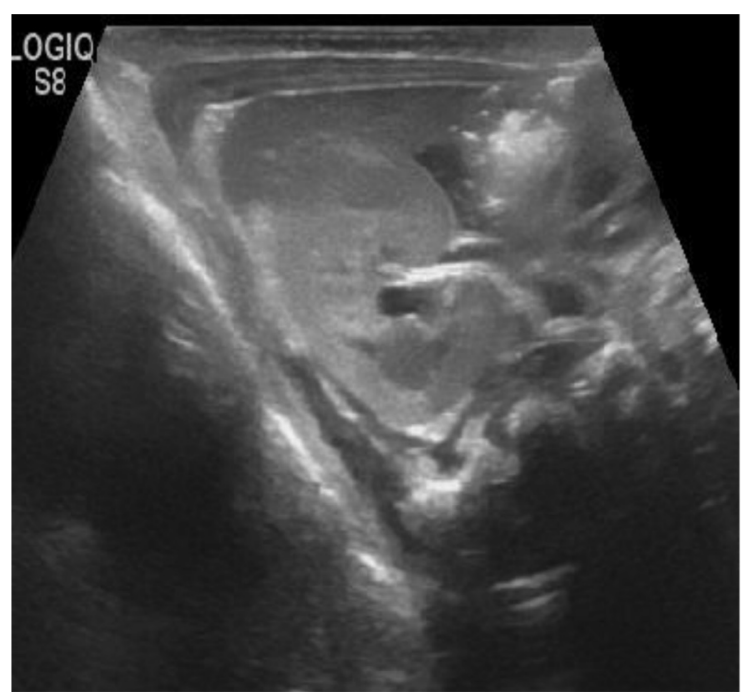

Fig2. Calcification of the renal artery

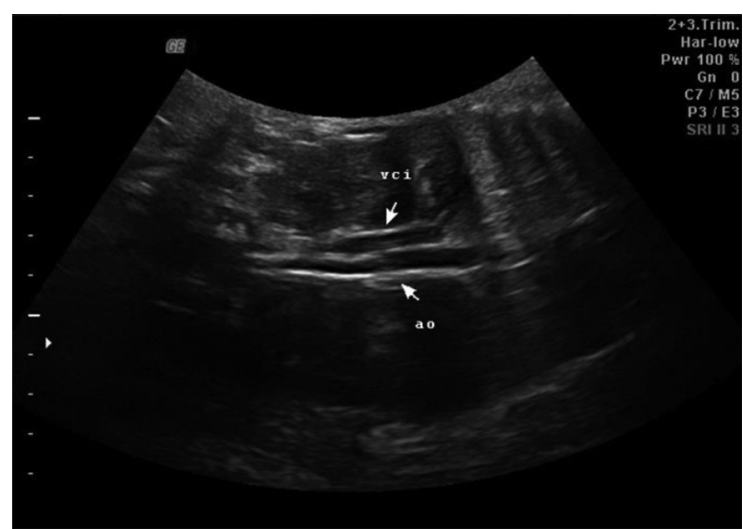

Fig3. Fetal echocardiogram shows echogenic and calcified descending aorta (Ao)

male baby with congenital hydrocephalus. It may be plausible to think the reason of nonimmune hydropic fetuses may be due to GACI as non-immune hydrops has been reported in infants with GACI ${ }^{10-12}$. However, both hydropic fetuses were aborted at 17 th gestational week and autopsy revealed no calcification in both fetuses. Calcification of vessels in fetal life results in decreased vessel compliance and hypertension leading to hypertrophy of the heart chambers and cardiac failure, hydrops fetalis. The first case is doing well, however our second patient had appeared asymptomatic until the age of 10 months when he presented with arterial hypertension; he is now on propranolol treatment. Unfortunately he has ST depression when he is agitated. Both of the patients are within the normal growth percentiles.

Human ENPP1 gene is compromised of 25 coding exons spanning approximately 87 $\mathrm{kb}$ region on chromosome 6q23. ENPP1 gene protein product NPP1, which includes approximately 920 residues with a molecular weight of $104 \mathrm{kDa}$, is a type II transmembrane protein consisting of a small intracellular region (between 10 and 80 residues) and a larger extracellular domain (830 residues), which contains the catalytic site. This catalytic site has phosphodiesterase/phosphotransferase activity, which is crucial for the hydrolysis of pyrophosphate bonds (for example, in ATP) and phosphodiester bonds (for example, in oligonucleotides) to produce nucleoside 5 '-monophosphates 2,13 . The homozygous W322X (termination) (c.966G $>$ A at exon 9) mutation that we detected in the first case corresponds to the active site of the protein leading a truncated protein possibly with no or little activity due to the conversion of tryptophan coding sequence into a termination codon $^{14}$. Previously another point mutation at exon 9 was reported by Rutsch et al. ${ }^{1}$ which led to a termination codon (Y312X) giving rise to nonsense mediated decay. Interestingly, mouse ENNP1gene,which has $95 \%$ homology with its human counterpart, is also compromised of 25 coding exons spanning approximately $75 \mathrm{~kb}$ region encoding a 905 residue protein ${ }^{1}$. ENNP1 knockout mouse model was generated by introducing a mutation in the exon 9 of mouse ENNP1 gene, which abolishes the functional protein expression emphasizing the functional significance of exon 9 in ENPP1 function ${ }^{15}$. Moreover, the parents of this first case were also heterozygous for the same mutation with normal phenotypes. 
The second case has ENNP1 gene p.G738R (c.2212G $>$ A at exon 21) mutation, where glycine is converted into arginine ${ }^{13}$. This region corresponds to the extracellular endonuclease subunit of the protein. This extracellular endonuclease activity is required for the cleavage of single-and double-stranded nucleic acids. There are various studies reporting the mutations in this endonuclease subunit in patients with idiopathic infantile arterial calcification 2,16 . One of these reports from Rutsch et al. ${ }^{1}$ found a homozygous arginineto-cystein (R774C) mutation, due to a $2320 \mathrm{C}>\mathrm{T}$ transition at exon 22 , both in a Turkish boy with GACI and his father, who had hypophosphatemic rickets. Parents were consanguineous. The child had also periarticular calcification and was still alive at 3 years of age. However, this R774C mutation was then found to be a polymorphism by LorenzDepiereuxet al. ${ }^{17}$, who also restudied this family, and identified a different homozygosity for a G266V substitution at exon 8 in the ENPP1 gene in both father and the son. In another case of an Israeli Arab male patient with autosomal recessive hypophosphatemic rickets-2, Lorenz-Depiereuxet al. ${ }^{17}$ identified homozygosity for a 1-bp insertion (2248insA) in exon 22 of the ENPP1 gene, resulting in a frameshift and premature termination after 5 codons, disrupting most of the nuclease-like domain. Even though there is no report stating a mutation in exon 21 , there are various reports indicating mutations in exon 22 , which resides at the same protein subunit as exon 21 .

The synthetic PPi analogues, biphosphonates has been proposed to reduce calcification in GACI patients and have been tried in treatment $3,18,19$. The exact role of biphosphonates is not known. However in studies dealing with children with osteogenesis imperfecta, biphosphonates have been shown that they decrease phosphate levels, increase parathormone levels and cause stabile levels of calcium ${ }^{20}$. In Rutsch's study ${ }^{3}$, survival seems to be associated with hypophosphatemia linked with hyperphosphaturia in GACI patients $^{3}$. In this retrospective analysis of patients biphosphonate therapy was associated in survival in 11 of $17(65 \%)$ treated patients, compared to 8 of 26 (31\%) untreated patients(3). We have treated the present patients with intravenous pamidronate. Duration and doses of biphosphonate treatment remain unclear. We still treat them with pamidronate. Even though the inital symptoms were the same in both cases, first case responded well to PPi treatment with decreasing arterial calcification whereas the second case did not. This is probably due to fact that there is almost no enzyme activity interfering with the effect mechanism of PPi in the first case. As mentioned above, there are various members of the NPP family with different functional properties e.g. NPP1, hydrolyzes ATP whereas NPP3 hydrolyzes $\mathrm{PPi},{ }^{21,22}$ therefore it is possible that mutation in the second case render its activity so it hydrolyzes extracellular PPi interfering with its transport and intracellular effect. Another possibility is that mutation in the second case may structurally transform NPP1 to covalently bind to PPi and prevents its entry into cell.

In conclusion, we have reported two newborns with GACI with two new mutations who were treated with intravenous pamidronate and discussed their progression in the first year of life. To our knowledge there are no single nucleotide polymorphisms found in the altered regions and both mutations are reported for the first time in the literature.

\section{REFERENCES}

1. Rutsch F, Ruf N, Vaingankar S, et al. Mutations in ENNP1 are associated with "idiopathic" infantile arterial calcification. Nat Genet 2003; 34: 379-381.

2. www.omim.org/entry/208000

3. Rutsch F, Böyer P, Nitschke MS, et al. Hypophosphatemia, hyperphosphaturia, and biphosphonate treatment are associated with survival beyond infancy in generalized arterial calcification of infancy. CircCardiovasc Genet 2008; 1: 133-140.

4. Bollen M, Gijbers R, Ceulemans H, Stalmans W, Stefan C. Nucleotide pyrophosphatases/phosphodiesterases on the move. Crit Rev Biochem Mol Biol 2003; 35: 393-432.

5. Felisch H, Russell RG, Straumann F. Effect of pyrophosphate on hydroxyapatite and its implications in calcium homeostasis. Nature 1996; 212: 901-903.

6. Menten ML, Fetterman GH. Coronary sclerosis in infancy: report of three autopsied cases, two siblings. Am J Clin Path 1948; 805-810.

7. Glatz AC, Pawel BR, Hsu DT, Weinberg P, Chrisant MR. Idiopathic infantile arterial calcification: two case reports, a review of the literature and a role for cardiac transplantation. Pediatr Transplant 2006; 10: 225-233.

8. Chong CR, Hutchins GM. Idiopathic infantile arterial calcification: the spectrum of clinical presentations. Ped Develop Pathol 2008; 11: 405-415. 
9. Brachet $\mathrm{C}$, Mansbach AL, Clerckx A, Deltenre P, Heinrichs C. Hearing loss is a part of the clinical picture of ENPP1 loss of function mutation. Hormon Res Paediatr 2014; 81: 63-66.

10. Crade M, Lewis DF, Nageutte MP. In utero appearance of idiopathic infantile calcification: ultrasound study of a 28-week fetus. Ultrasound Obstet Gynecol 1991; 1: 284-285.

11. Nagar AM, Hanchate V, Tandon A, et al. Antenatal detection of idiopathic arterial calcification with hydrops fetalis. J Ultrasound Med 2003; 22: 653-659.

12. Heuser CC, Puchalski M, Kennedy A, et al. Radiographic and pathologic evaluation of idiopathic infantile arterial calcification. Obstet Gynecol 2010; 115: 465-468.

13. http://www.ensembl.org/index.html

14. http://www.mutationtaster.org/

15. Johnson K, Goding J, Van Etten D, et al. Linked deficiencies in extracellular PP(i) and osteopontin mediate pathologic calcification associated with defective PC-1 and ANK expression. J Bone Miner Res 2003;18:994-1004.

16. Mackenzie NC, Huesa C, Rutsch F, MacRae VE. New insights into NPP1 function: lessons from clinical and animal studies. Bone 2012; 51: 961-968.
17. Lorenz-Depiereux B, Schnabel D, Tiosano D, Häusler G, Strom TM. Loss-of-function ENPP1 mutations cause both generalized arterial calcification of infancy and autosomal-recessive hypophosphatemic rickets.Am J Hum Genet 2010 12; 86: 267-272.

18. Cheng KS, Chen MR, Ruf N, Lin SP, Rutsch F. Generalized arterial calcification of infancy: different clinical courses in two affected siblings. Am J Med Genet A 2005; 136: 210-213.

19. Ramjan KA, Roscioli T, Rutsch F, Sillence D, Munns CF. Generalized arterial calcification of infancy: treatment with biphosphonates. Nat Clin Pract Endocrinol Metab 2009; 5: 167-172.

20. Rauch F, Plotkin H, Travers R, Zeitlin L, Glorieux FH Osteogenesis imperfecta types I, III and IV: effect of pamidronatetheraphy on bone and mineral metabolism. J ClinEndocrinol Metab 2003; 88: 986-992.

21. h t t p : / / w w w . n a t u r e.com / bon e k e y / knowledgeenvironment/2011/1106/bonekey20110516/ full/bonekey20110516.html

22. Villa-Bellosta R, Wang X, Millán JL, Dubyak GR, O'Neill WC. Extracellular pyrophosphate metabolism and calcification in vascular smooth muscle.Am J Physiol Heart Circ Physiol 2011; 301: H61-H68. 